\title{
Estimation of the ideal correction of lumbar lordosis to prevent reoperation for symptomatic adjacent segment disease after lumbar fusion in older people
}

\author{
Shan-Jin Wang ${ }^{\dagger}$, Shu-Bao Zhang ${ }^{\dagger}$, Yu-Yang Yi, Hao-Wei Xu ${ }^{*}$ and De-Sheng Wu
}

\begin{abstract}
Background: Symptomatic adjacent segment disease (ASDis) is a major complication following spinal fusion. Sagittal spinopelvic imbalance may contribute to the development of ASDis. However, the exact ideal correction of lumbar lordosis (LL) is unknown for different ages of people to prevent ASDis. The purpose of this study was to estimate the ideal correction of LL required to prevent symptomatic ASDis requiring revision surgery in patients of various ages, and to determine the radiographic risk factors for ASDis.

Methods: 468 patients who underwent lumbar fusion between January 2014 and December 2016, were enrolled in the present study. The patients were classified into the ASDis and N-ASD group. These two matched groups were compared regarding surgery-related factors and radiographic features. Multivariate logistic regression analysis was used to evaluate the risk factors for ASDis.

Results: Sixty-two patients (13.25\%) underwent reoperation for ASDis during a mean follow-up duration of 38.07 months. Receiver operating characteristic curve analysis showed that the postoperative $\mathrm{LL}$ - preoperative $\mathrm{LL}(\Delta \mathrm{LL})$ cutoff value was $11.7^{\circ}$ for the development of ASDis. Logistic regression analysis revealed that the risk factors for symptomatic ASDis were a smaller $\mathrm{LL}$ angle, $\Delta \mathrm{LL}>12^{\circ}$, and $\mathrm{PI}-\mathrm{LL}>10^{\circ}(p<0.05)$. For patients $>60$ years, the incidence of ASDis was higher in patients with a LL correction of $\geq 10^{\circ}$ and a lumbar-pelvic mismatch (PI-LL) of $>20^{\circ}$.

Conclusions: The significant predictors of the occurrence of ASDis were a smaller $\mathrm{LL}$ angle, $\Delta \mathrm{LL}>12^{\circ}$, and PI-LL $>10^{\circ}$. However, in patients older than 60 years, the incidence of ASDis after lumbar fusion was higher in those with a LL correction of $\geq 10^{\circ}$ and $\mathrm{PI}-\mathrm{LL}$ of $>20^{\circ}$. More attention should be paid to patient age and the angle of correction of $\mathrm{LL}$ before lumbar fusion.
\end{abstract}

Keywords: Lumbar fusion, Symptomatic adjacent segment disease, Disc degeneration, Correction of lumbar lordosis, Risk factor

\footnotetext{
* Correspondence: spine1122@163.com

'Shan-Jin Wang and Shu-Bao Zhang are co-first authors.

Department of Spinal Surgery, Shanghai East Hospital, Tongji University

School of Medicine, 150\# Jimo RD, Pudong New Area, Shanghai 200120,

China
}

C C The Author(s). 2020 Open Access This article is licensed under a Creative Commons Attribution 4.0 International License, which permits use, sharing, adaptation, distribution and reproduction in any medium or format, as long as you give appropriate credit to the original author(s) and the source, provide a link to the Creative Commons licence, and indicate if changes were made. The images or other third party material in this article are included in the article's Creative Commons licence, unless indicated otherwise in a credit line to the material. If material is not included in the article's Creative Commons licence and your intended use is not permitted by statutory regulation or exceeds the permitted use, you will need to obtain permission directly from the copyright holder. To view a copy of this licence, visit http://creativecommons.org/licenses/by/4.0/. The Creative Commons Public Domain Dedication waiver (http://creativecommons.org/publicdomain/zero/1.0/) applies to the data made available in this article, unless otherwise stated in a credit line to the data. 


\section{Background}

With the rapid development of spinal surgery techniques, spinal fusion has become an established and common treatment for lumbar degenerative disease (LDD). However, long-term studies have found that adjacent segment degeneration (ASD) is common after lumbar fusion, with radiological ASD seen in 36-100\% of patients and symptomatic ASD seen in $0-27.5 \%$ of patients [1-3]. There is no definitive gold standard for the diagnosis of ASD, but the most common manifestation of ASD is intervertebral disc degeneration at adjacent segments. ASD also includes segment instability, facet joint hyperplasia, and spinal canal stenosis. LDD frequently causes low back pain (LBP), and the economic cost of diagnosing and treating LBP in the United States is estimated at about $\$ 90$ billion per year [4]. There is a high incidence of reoperation for ASD after spinal fusion, which may bring a great economic burden.

Although many studies have investigated the pathomechanism of ASD after spinal fusion, the conclusions are still controversial. Lumbar fusion may increase the stress on the nonoperative adjacent segments, leading to ASD in long-term follow-up [5]. However, ASD may be caused by natural degeneration of the spine. In addition, patient factors such as older age, obesity, pre-existing ASD, facet degeneration, and lumbar amyotrophy may contribute to the development of ASD [6]. Recent studies have shown that the sagittal spinopelvic balance significantly affects the clinical therapy of patients with LBP $[7,8]$. LDD are often associated with spinopelvic imbalance. A decrease in lumbar lordosis (LL) is related to LBP, and overcorrection of LL is an effective therapeutic modality to maintain optimal sagittal alignment in patients with degenerative lumbar kyphosis $[9,10]$. Patients with a pelvic incidence-LL (PI$\mathrm{LL})$ mismatch $\left(\mathrm{PI}-\mathrm{LL} \geq 10^{\circ}\right.$ ) are 10 times more likely to develop ASD than patients with a PI-LL of $<10^{\circ}$ [11]. However, sagittal spinopelvic alignment often changes with age, as older adult patients compensate for LL loss by allowing the trunk to pitch forward [12]. Thus, excessive pursue ideal alignment objectives are counterproductive for older adults.

The present study aimed to evaluate whether the incidence of reoperation for ASD after posterior vertebral fusion was associated with the age at the time of surgery and various pelvic parameters. Furthermore, we aimed to estimate the ideal correction of LL to prevent symptomatic ASD, optimize the clinical treatment plan, and improve the treatment effect.

\section{Methods}

\section{Study population}

The present study received ethical approval from the Ethics Committee Board of the participating hospital. We reviewed 667 patients who underwent posterolateral fusion (PLF) or posterior lumbar interbody fusion (PLIF) for LDD between January 2014 and December 2016. All patients under general anesthesia, classic posterior lumbar fixation fusion procedure was performed. Posterior lumbar pedicle screw internal fixation, laminectomy and nerve decompression. During the operation, more attention to avoid injury of the adjacent facet joints. Intervertebral, intertransverse and posterolateral bone graft were used for fusion. All patients used the same surgical implant instruments.

The inclusion criteria for patients in the reoperation group were: (1) symptomatic ASD disease diagnosed in patients with LBP, intermittent claudication, radiculopathy, or lower extremity muscle strength weakness that matched the radiographic ASD features (lumbar spinal stenosis or lumbar spondylolisthesis, disc degeneration, facet joint osteoarthritis); (2) complete imaging data; (3) primary lumbar fusion level between L1 and L5 for LDD. The exclusion criteria were: (1) lumbar trauma, infection, tumor, or congenital deformity; (2) sagittal vertical axis (SVA) > $5 \mathrm{~cm}$ or degenerative lumbar scoliosis $>20^{\circ}$; (3) refusal to participate in this study.

Four-hundred-and-sixty-eight patients were enrolled. The mean follow-up duration was 38.07 months. Of these

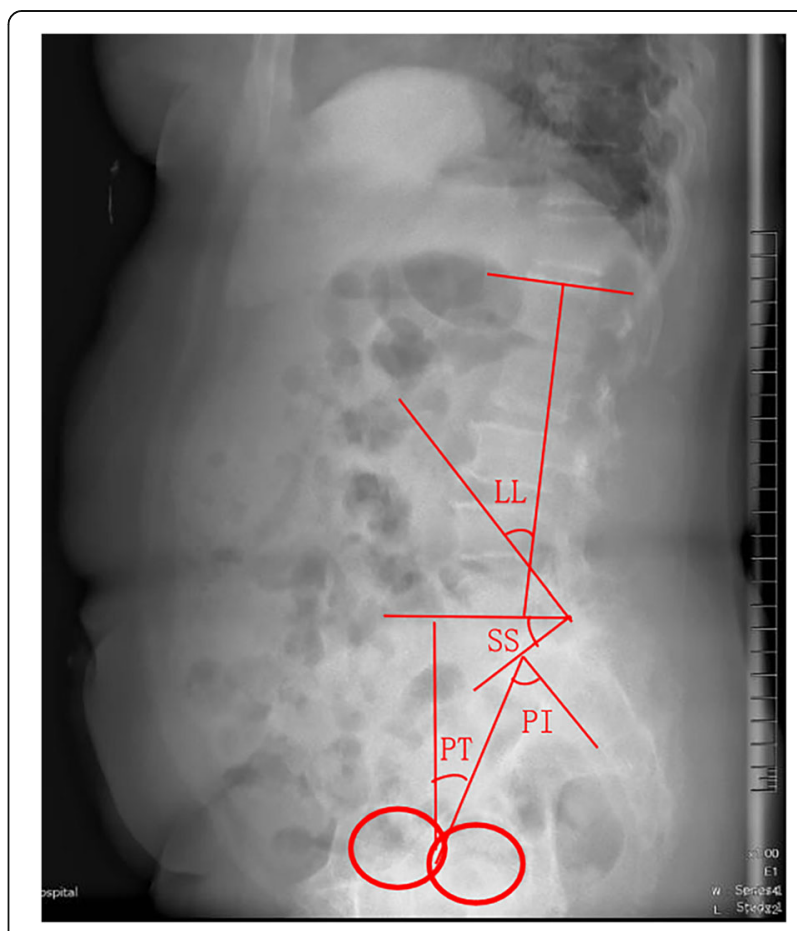

Fig. 1 Methods for measuring the pelvic parameters. Lumbar lordosis (LL): angle between the superior endplate line of $\mathrm{L} 1$ and S1. Pelvic incidence (PI): angle between the perpendicular to the sacral plate at its midpoint and the line connecting this point to the middle axis of the femoral heads. Sacral slope (SS): angle between the superior plate of S1 and a horizontal line. Pelvic tilt (PT) $=$ PI-SS 
468 patients, 74 (15.81\%) developed asymptomatic ASD, $62(13.25 \%)$ required reoperation for symptomatic ASD after failure of conservative therapy including medication and/or physical treatment (ASDis group). These 62 patients were matched in a 1:1 ratio by sex, age, body mass index (BMI), follow-up duration, and other factors with enrolled patients who underwent posterior lumbar fusion but did not develop ASD (N-ASD group). The groups were created with similar distributions of matched variables to minimize selection bias before the radiographic and magnetic resonance imaging (MRI) measurements.

\section{Data collection}

Plain radiography and MRI showed no degeneration or instability in the adjacent segments before the primary operation. Standing lumbar spine lateral radiographs (including the bilateral femoral heads) were taken for all patients. 1 week before and after surgery, pre- and postoperative sagittal spinopelvic parameters were measured to determine the SVA, LL, PI, sacral slope, pelvic tilt (PT), and PI-LL (Fig. 1); $\triangle$ LL was calculated as absolute value of the difference between the postoperative LL and the preoperative LL $(\triangle \mathrm{LL}=\mid$ Postoperative LL - Preoperative LL $\mid)$. On MRI, all patients in the ASD group had a Pfirrmann [13] disc degeneration grade of $\geq$ III at the adjacent

Table 1 Comparison of patient characteristics between ASDis group and N-ASD group

\begin{tabular}{|c|c|c|c|c|}
\hline Characteristic & ASDis $(n=62)$ & $N-A S D(n=62)$ & $x^{2} / t$ & $p$ \\
\hline Age, year & $61.65 \pm 8.43$ & $61.39 \pm 8.14$ & 0.17 & 0.863 \\
\hline BMI, kg/m ${ }^{2}$ & $24.75 \pm 3.27$ & $24.73 \pm 3.20$ & 0.03 & 0.975 \\
\hline $\operatorname{Sex}(M / F)$ & $25 / 37$ & $25 / 37$ & 0 & 1 \\
\hline Diabetes (Y) & 19 (30.6\%) & $20(32.3 \%)$ & 0.04 & 0.847 \\
\hline Hypertension (Y) & $34(54.8 \%)$ & 25 (40.3\%) & 2.62 & 0.106 \\
\hline Smoking $(Y)$ & $8(12.9 \%)$ & $9(14.5 \%)$ & 0.07 & 0.794 \\
\hline Drinking $(Y)$ & $8(12.9 \%)$ & $10(16.1 \%)$ & 0.26 & 0.610 \\
\hline Lumbar BMD (T scores) & $-1.66 \pm 1.33$ & $-1.34 \pm 1.40$ & -1.29 & 0.2 \\
\hline Follow-up (months) & $37.98 \pm 6.93$ & $38.35 \pm 8.04$ & -0.275 & 0.784 \\
\hline \multicolumn{5}{|l|}{ Disease } \\
\hline DS & $30(48.4 \%)$ & $22(35.5 \%)$ & 3.23 & 0.199 \\
\hline FS & $20(32.3 \%)$ & $20(32.3 \%)$ & & \\
\hline $\mathrm{DH}$ & $12(19.4 \%)$ & $20(32.3 \%)$ & & \\
\hline \multicolumn{5}{|l|}{ Fusion method } \\
\hline PLF & $38(61.3 \%)$ & $33(53.2 \%)$ & 0.824 & 0.364 \\
\hline PLIF & $24(38.7 \%)$ & $29(46.8 \%)$ & & \\
\hline \multicolumn{5}{|l|}{ Segments fused } \\
\hline$\leq 2$ segments & $29(46.8 \%)$ & $27(43.5 \%)$ & 0.13 & 0.718 \\
\hline$>2$ segments & $33(53.2 \%)$ & 35 (56.5\%) & & \\
\hline
\end{tabular}

segment and spinal canal stenosis (defined as a spinal canal midsagittal diameter of $<12 \mathrm{~mm}$ ) [14]. Interviews and questionnaires were used to determine patient age, sex, BMI, smoking status, presence of hypertension, presence of diabetes mellitus, and drinking status.

\section{Statistics}

Data of the abovementioned sagittal parameters were statistically analyzed using SPSS 25 (SPSS Inc., Chicago, IL, USA). We selected the controls using propensity scorematched (PSM) analyses, the 1:1 nearest neighbor technique with a small caliper of 0.2 to ensure better balance. Values were described as the mean \pm standard deviation. If the data were normally distributed, the independent sample t-test was adopted to compare the ASD group and the $\mathrm{N}$-ASD group. The Mann-Whitney U test was used to analyze differences in pelvic sagittal parameters that were non-normally distributed. Count data were analyzed using the chi-square test. The threshold value of positive results were obtained by receiver operating characteristic curve analysis and area under the curve quantitative analysis. After univariate analyzed, variables with statistically significant differences $(p<0.05)$ were incorporated into the multivariate logistic regression model. Multivariate logistic regression analysis was used to identify the risk factors for ASD. $p<0.05$ was considered statistically significant.

Table 2 Univariate analysis comparing radiographic variables between patients with and without adjacent segment disease

\begin{tabular}{|c|c|c|c|c|}
\hline Characteristic & ASDis $(n=62)$ & $N-A S D(n=62)$ & $x^{2} / t$ & $p$ \\
\hline \multicolumn{5}{|l|}{$\mathrm{LL}\left({ }^{\circ}\right)$} \\
\hline Preoperative & $37.94 \pm 13.11$ & $44.00 \pm 8.74$ & -3.02 & 0.003 \\
\hline Postoperative & $38.14 \pm 13.81$ & $44.98 \pm 9.41$ & -3.23 & 0.002 \\
\hline \multicolumn{5}{|l|}{$\mathrm{SS}\left({ }^{\circ}\right)$} \\
\hline Preoperative & $36.37 \pm 10.35$ & $34.18 \pm 7.99$ & 1.32 & 0.189 \\
\hline Postoperative & $33.41 \pm 10.13$ & $31.81 \pm 9.10$ & 0.923 & 0.358 \\
\hline \multicolumn{5}{|l|}{$\operatorname{PT}\left({ }^{\circ}\right)$} \\
\hline Preoperative & $18.15 \pm 11.64$ & $17.19 \pm 10.37$ & 0.485 & 0.629 \\
\hline Postoperative & $21.12 \pm 10.32$ & $19.46 \pm 9.26$ & 0.941 & 0.348 \\
\hline $\mathrm{PI}\left({ }^{\circ}\right)$ & $54.52 \pm 10.45$ & $51.37 \pm 12.06$ & 1.56 & 0.122 \\
\hline \multicolumn{5}{|l|}{ PI-LL $\left({ }^{\circ}\right)$} \\
\hline Preoperative & $16.58 \pm 13.22$ & $7.37 \pm 11.06$ & 4.21 & $<0.001$ \\
\hline Postoperative & $16.38 \pm 13.10$ & $6.28 \pm 14.19$ & 4.12 & $<0.001$ \\
\hline$\Delta \mathrm{LL}\left({ }^{\circ}\right)$ & $12.18 \pm 6.79$ & $7.74 \pm 5.06$ & 4.13 & $<0.001$ \\
\hline \multicolumn{5}{|c|}{ Preexisting spinal stenosis at adjacent segment } \\
\hline Yes & $32(51.6 \%)$ & $24(38.7 \%)$ & 2.08 & 0.149 \\
\hline No & $30(48.4 \%)$ & $38(61.3 \%)$ & & \\
\hline \multicolumn{5}{|c|}{ Preexisting disc degeneration at adjacent segment } \\
\hline Yes & $24(38.7 \%)$ & $16(25.8 \%)$ & 2.36 & 0.124 \\
\hline No & 38 (61.3\%) & $46(74.2 \%)$ & & \\
\hline
\end{tabular}

$\Delta \mathrm{LL}=\mid$ Postoperative $\mathrm{LL}$ - Preoperative $\mathrm{LL} \mid$ 
Table 3 Comparing correlation of postoperative pelvic parameter between patients with and without adjacent segment disease in different age groups

\begin{tabular}{|c|c|c|c|c|c|c|}
\hline \multirow[t]{2}{*}{ Pelvic parameter } & \multicolumn{2}{|l|}{ Age $\leq 60$} & \multirow[b]{2}{*}{$P$} & \multicolumn{2}{|l|}{ Age $>60$} & \multirow[b]{2}{*}{$P$} \\
\hline & $\begin{array}{l}\text { ASDis } \\
(n=28)\end{array}$ & $\mathrm{N}-\mathrm{ASD}(\mathrm{n}=28)$ & & $\begin{array}{l}\text { ASDis } \\
(n=34)\end{array}$ & $\begin{array}{l}\text { N-ASD } \\
(n=34)\end{array}$ & \\
\hline$\overline{\mathrm{LL}\left({ }^{\circ}\right)}$ & $39.45 \pm 9.31$ & $45.06 \pm 11.17$ & 0.046 & $37.06 \pm 16.71$ & $44.92 \pm 7.84$ & 0.016 \\
\hline SS $\left(^{\circ}\right)$ & $37.90 \pm 9.10$ & $34.41 \pm 7.76$ & 0.419 & $35.27 \pm 10.87$ & $30.80 \pm 9.53$ & 0.076 \\
\hline PT $\left(^{\circ}\right)$ & $22.61 \pm 12.47$ & $18.70 \pm 9.36$ & 0.190 & $19.88 \pm 8.14$ & $20.08 \pm 9.27$ & 0.926 \\
\hline $\operatorname{PI}\left({ }^{\circ}\right)$ & $53.77 \pm 9.89$ & $51.74 \pm 11.69$ & 0.488 & $55.15 \pm 10.99$ & $50.87 \pm 12.60$ & 0.141 \\
\hline \multicolumn{7}{|l|}{ PI-LL $\left(^{\circ}\right)$} \\
\hline$<10$ & $6(21.4 \%)$ & 15 (53.6\%) & 0.045 & $10(29.4 \%)$ & $17(50 \%)$ & 0.025 \\
\hline $10-20$ & $16(57.1 \%)$ & $9(32.1 \%)$ & & $12(35.3 \%)$ & $14(41.2 \%)$ & \\
\hline$>20$ & $6(21.5 \%)$ & $4(14.3 \%)$ & & 12 (35.3\%) & $3(8.8 \%)$ & \\
\hline \multicolumn{7}{|l|}{$\Delta \mathrm{LL}\left({ }^{\circ}\right)$} \\
\hline$<10$ & $16(57.1 \%)$ & 20 (71.4\%) & 0.497 & 12 (35.3\%) & $23(67.6 \%)$ & 0.027 \\
\hline $10-20$ & $8(28.6 \%)$ & $6(21.4 \%)$ & & 17 (50\%) & $9(26.5 \%)$ & \\
\hline$>20$ & $4(14.3 \%)$ & $2(7.1 \%)$ & & $5(14.7 \%)$ & 2 (5.9\%) & \\
\hline
\end{tabular}

\section{Results}

\section{General situation}

Before the initial surgery, there were 30 patients $(48.4 \%)$ with degenerative spondylolisthesis, 12 (19.4\%) with degenerative disc herniation, and 20 (32.3\%) with foraminal stenosis in ASD groups (Table 1). During the 3-years follow-up, 44 patients (70.97\%) had ASD at the cranial adjacent segment, while 18 (29.03\%) had ASD at the

Table 4 Result from Univariate and multivariate logistic regression analysis for potential risk factors for ASDis

\begin{tabular}{|c|c|c|c|c|}
\hline \multirow[b]{2}{*}{ Variables } & \multicolumn{2}{|l|}{ Univariate } & \multicolumn{2}{|l|}{ Multivariate } \\
\hline & OR $(95 \% \mathrm{Cl})$ & $p$ & OR $(95 \% \mathrm{Cl})$ & $p$ \\
\hline $\begin{array}{l}\text { Lumbar BMD } \\
\text { (T scores) }\end{array}$ & $0.84(0.64-1.10)$ & 0.2 & - & - \\
\hline Postoperative LL $\left(^{\circ}\right)$ & $0.95(0.92-0.99)$ & 0.005 & $0.96(0.92-0.99)$ & 0.023 \\
\hline Postoperative SS $\left(^{\circ}\right)$ & $1.02(0.98-1.06)$ & 0.355 & - & - \\
\hline Postoperative PT $\left({ }^{\circ}\right)$ & $1.02(0.98-1.06)$ & 0.346 & - & - \\
\hline Postoperative $\mathrm{PI}\left({ }^{\circ}\right)$ & $1.03(0.99-1.06)$ & 0.114 & - & - \\
\hline \multicolumn{5}{|l|}{ Postoperative PI-LL $\left(^{\circ}\right)$} \\
\hline$<10$ & Reference & & & \\
\hline$>10$ & $2.82(1.34-5.97)$ & 0.007 & $2.72(1.22-6.04)$ & 0.014 \\
\hline \multicolumn{5}{|l|}{$\Delta \mathrm{LL}\left({ }^{\circ}\right)$} \\
\hline$<12$ & Reference & & & \\
\hline$>12$ & $3.43(1.58-7.45)$ & 0.002 & $3.11(1.37-7.08)$ & 0.007 \\
\hline $\begin{array}{l}\text { Preexisting disc } \\
\text { degeneration } \\
\text { at adjacent segment }\end{array}$ & $1.82(0.85-3.90)$ & 0.126 & - & - \\
\hline $\begin{array}{l}\text { Preexisting spinal } \\
\text { stenosis at adjacent } \\
\text { segment }\end{array}$ & $1.69(0.83-3.45)$ & 0.15 & - & - \\
\hline Segments fused & $1.14(0.56-2.31)$ & 0.718 & - & - \\
\hline Fusion method & $1.39(0.68-2.84)$ & 0.365 & - & - \\
\hline
\end{tabular}

caudal adjacent segment. The ASD group included 37 females and 25 males with an average age of 65.8 years. In the ASD group, there were 24 cases of PLIF and 38 cases of PLF; in the N-ASD group, there were 29 cases of PLIF and 33 cases of PLF. In the ASD group, the surgery level was L4-L5 in 26 patients, L3-L5 in 23, and L2L5 in 13; in the N-ASD group, the surgery level was L4L5 in 21, L3-L5 in 20, and L2-L5 in 21. There were no significant differences between the two groups regarding

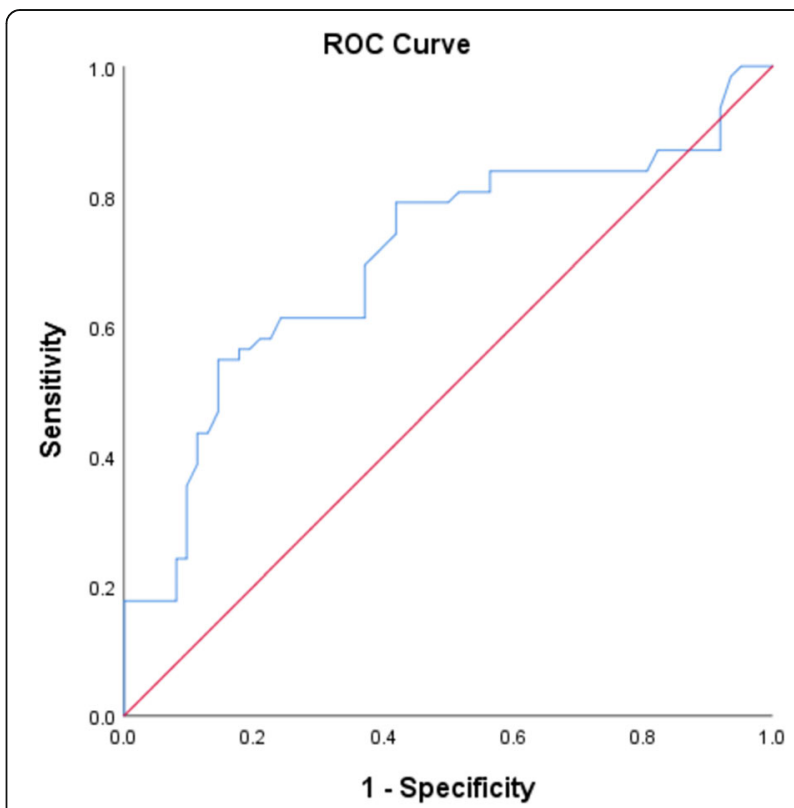

Fig. 2 Logistic regression and receiver operating characteristic curve analysis show a cut-off value for postoperative change in lumbar lordosis ( $\Delta \mathrm{LL}$ ) of $11.7^{\circ}$ at which the classification based on $\Delta \mathrm{LL}$ yields a sensitivity of $58 \%$ and specificity of $86 \%$. The area under the curve is 0.703 , with a confidence interval of 0.608 to 0.798 
baseline data such as sex, age, BMI, smoking status, basic diseases, follow-up duration, number of cages, and surgical level (Table $1, p>0.05$ ).

\section{Relationship between age and ASD based on radiological outcomes}

Radiologic measurements of the preexisting spinal stenosis and disc degeneration at the adjacent segments showed that the degree of preoperative LDD did not significantly differ between the ASD and N-ASD groups (Table 2). Among the preoperative spinal parameters, the PI-LL was larger in the ASD group compared with the N-ASD group $(16.58 \pm 13.22$ vs $7.37 \pm 11.06$, $p<0.001)$. After surgery, the ASD group had a significantly smaller LL $(38.14 \pm 13.81$ vs $44.98 \pm 9.41, p=$ $0.002)$ and larger PI-LL $(16.38 \pm 13.10$ vs $6.28 \pm 14.19$, $p<0.001)$ than the N-ASD group. The $\triangle \mathrm{LL}$ was also larger in the ASD group than the N-ASD group (12.18 \pm 6.79 vs $7.74 \pm 5.06, p<0.001$ ) (Table 2 ). The correlation between the PI-LL angle and $\triangle \mathrm{LL}$ was analyzed. In patients $>60$ years of age, when both PI-LL and $\triangle \mathrm{LL}$ were divided into three groups (cut-off value of $10^{\circ}$ and $20^{\circ}$ ), the differences between the ASD and N-ASD groups were statistically significant (Table 3 ). When PI-LL was divided into two groups, the cut-off value of $20^{\circ}(p=0.008)$ instead of $10^{\circ}(p=0.083)$ was statistically significant. When $\triangle \mathrm{LL}$ was divided into two groups, the cut-off value of $10^{\circ}(\mathrm{p}=$ $0.008)$ instead of $20^{\circ}(p=0.231)$ was statistically significant. However, in patients $\leq 60$ years of age, a high prevalence of ASD was significantly associated with PI-LL $\geq 10^{\circ}(p=$ 0.013), and $\triangle$ LL was not associated with ASD.

\section{Logistic regression analysis}

Multivariate logistic regression analysis was performed to determine the relative impact of radiographic features on the incidence of ASD. After adjusting for the variables age, BMI, sex, PI-LL, $\triangle$ LL, surgical level, number of fused segments, preexisting disc degeneration, and preexisting spinal stenosis at the adjacent segment, the variables that were associated with the development of ASD were a small postoperative LL angle $(\mathrm{OR}=0.96$, $p=0.023), \mathrm{PI}-\mathrm{LL}>10^{\circ}(\mathrm{OR}=2.72, p=0.014)$, and $\Delta \mathrm{LL}>$ $12^{\circ}(\mathrm{OR}=3.11, p=0.007)$ (Table 4$)$. The receiver operating characteristic curve analysis for measurements of $\triangle$ LL revealed that a cutoff value of $11.7^{\circ}$ was able to distinguish between the two groups with the highest sensitivity and specificity, with an area under the curve of 0.703 (95\% confidence interval 0.608-0.798) (Fig. 2).

\section{Discussion}

The maintenance of spinopelvic alignment is most important for adults with spinal deformity, as this is the

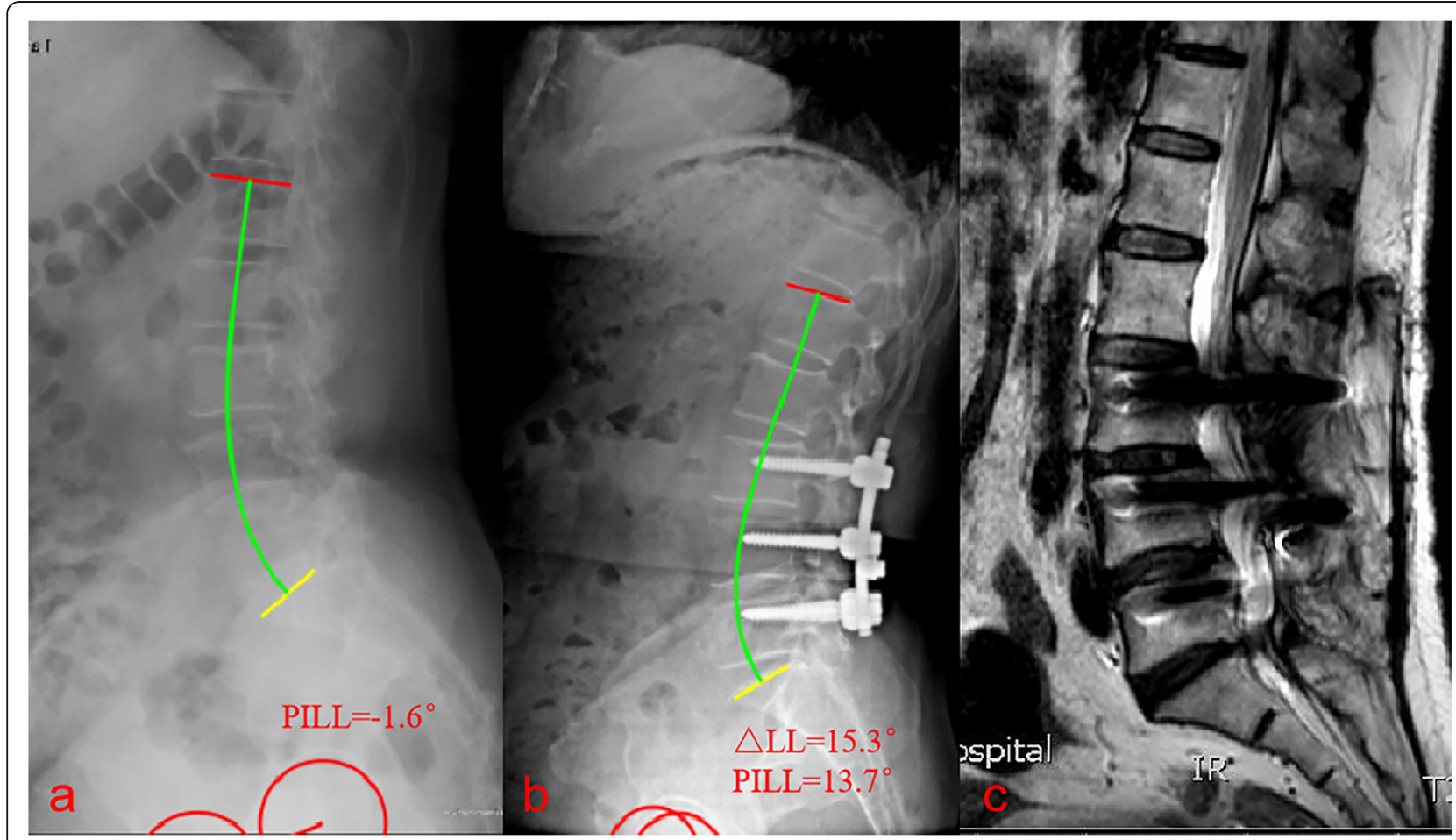

Fig. 3 Images from a 65-year-old man who underwent three-segment spinal fusion. a Preoperative radiograph. b 1-week postoperative radiograph. c MRI revealing the development of symptomatic adjacent segment disease at 3 years and 5 months postoperatively. Preoperatively, the pelvic incidence to lumbar lordosis mismatch (PI-LL) was $-1.6^{\circ}$. Postoperatively, the PI-LL was $13.7^{\circ}$ and the change in lumbar lordosis was $15.3^{\circ}$. Patients (age $>60$ ) with a change in lumbar lordosis of $>10^{\circ}$ were significantly more likely to develop adjacent segment disease 
primary determinant of life quality after corrective surgery [15]. However, sagittal imbalance reportedly increases the probability of ASD after spinal fusion for LDD [7]. LL is important for maintaining sagittal balance and upright posture. The most widely-used method of measuring LL is to measure the Cobb angle between the upper endplate of L1 and the upper endplate of S1 in the standing position. Currently, the relationships between LL and age, sex, and other factors are unclear; however, LL is positively correlated with lumbar spondylolisthesis and spondylolysis, and negatively correlated with LBP $[10,15]$. Failure to maintain normal LL may also increase the incidence of facet arthritis [16]. If the LL is small, this increases the risk of sagittal imbalance after surgery and is a predictor of ASD [17], which is similar to our findings. Thus, restoration of the physiological curvature of the lumbar spine is very important in improving patient quality of life and preventing postoperative complications.

The spinopelvic balance plays an important role in LDD. Several formulas have been created to evaluate the ideal LL to be reestablished in lumbar fusion surgery in different populations. Based on Legaye's formula in Korean patients [18], Lee et al. [9] found that overcorrection of LL (postoperative LL angle > ideal LL) effectively maintains the optimal SVA in patients with degenerative lumbar kyphosis during a minimum 2-year follow-up. Considering the effect of age, $\mathrm{Xu}$ et al. [19] determined the predictive formula for the ideal LL in Chinese adults as: $\mathrm{LL}=0.508 \times \mathrm{PI}-0.088 \times$ age +28.6 . Therefore, the surgical reconstruction of the ideal LL must consider variables such as age and ethnicity. Given that the normal range of LL varies widely (18.5-72.3 using the Cobb method) [20], it is difficult to estimate the normal/optimal LL angle for an individual.

There is not enough existing knowledge to accurately reconstruct the lordotic curvature. Our study attempted to explore the relationship between the $\triangle \mathrm{LL}$ and the need for reoperation for ASD after lumbar fusion in patients of different ages. A $\triangle \mathrm{LL}$ of $>10^{\circ}$ was associated with an increased risk of ASD in patients $>60$ years old (Fig. 3), but not in patients $\leq 60$ years old. This suggests that surgeons should not markedly change the LL angle in older adults. No previous study has investigated the effect of the postoperative change in LL on the prevention of ASD. However, the regional Cobb angle of L4-S1 is reportedly a crucial factor affecting the formation of LL [20], and a review of the data from 274 patients

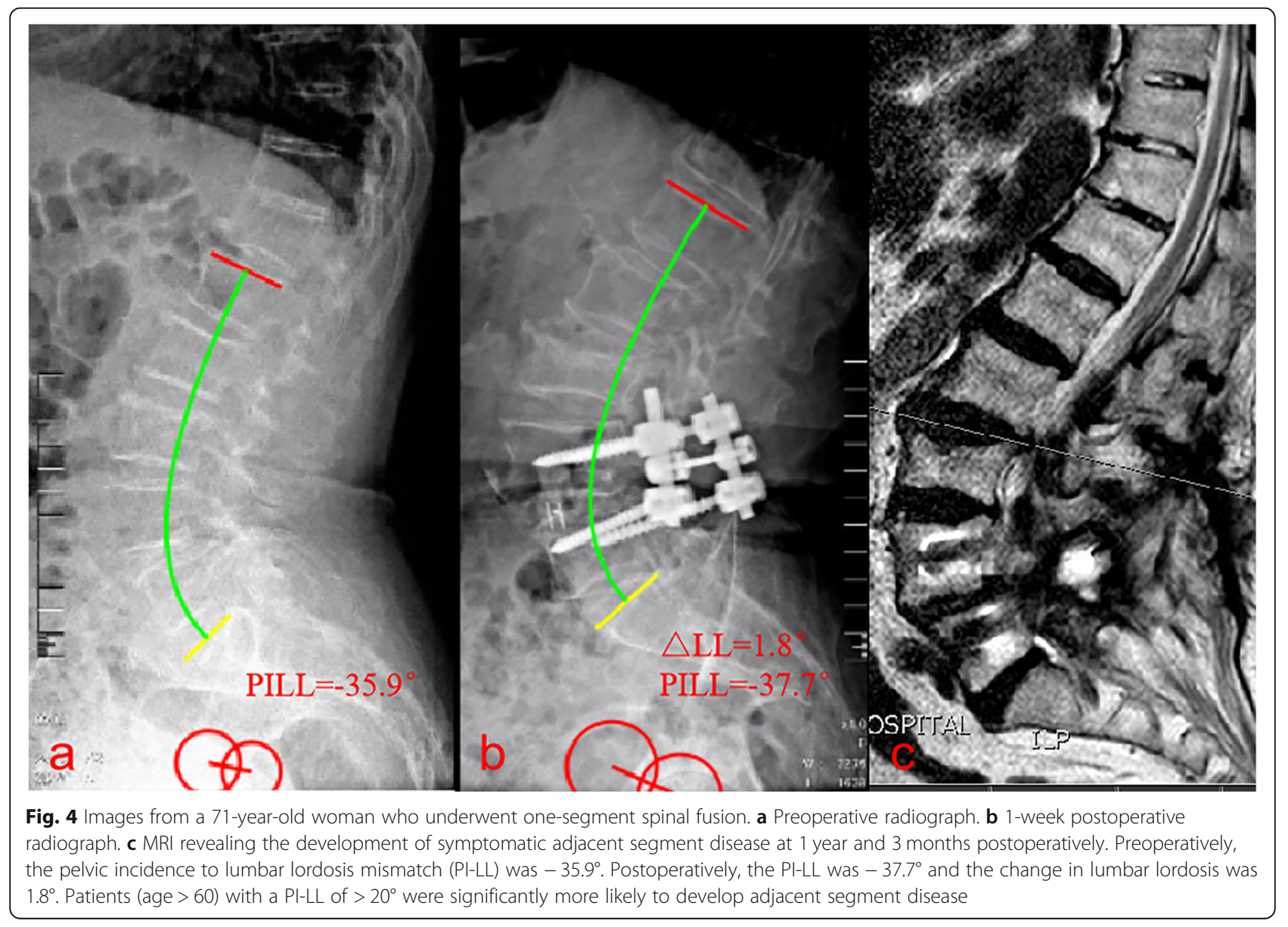


found that a postoperative L4-S1/L1-S1 lordosis ratio of $<50 \%$ increased the prevalence of ASD [21]. Further studies are required to confirm the ideal correction of the L4-S1/L1-S1 lordosis ratio and $\triangle \mathrm{LL}$.

A recent study reported that the variables most related to severe disability (Oswestry Disability Index $>40$ ) due to adult spinal deformity are a PT of $>22^{\circ}$, SVA of $>47$ $\mathrm{mm}$, and PI-LL of $>11^{\circ}$ [22]. Based on age-specific Oswestry Disability Index values, a subsequent study revealed that the ideal spinopelvic alignment values for patients aged $<35$ years are a PT of $10.9^{\circ}$, PI-LL of $10.5^{\circ}$, and SVA of $4.1 \mathrm{~mm}$, while those for patients aged $>75$ years are a PT of $28.5^{\circ}$, PI-LL of $16.7^{\circ}$, and SVA of 78.1 $\mathrm{mm}$ [12]. PI-LL mismatch can also be used to predict the incidence of ASD after spinal fusion surgery. Rothenfluh et al. [11] reported that patients with a PI-LL of $\geq 10^{\circ}$ were 10 times more likely to undergo revision surgery than those with a PI-LL of $<10^{\circ}$. Sagittal imbalance after lumbar fusion may increase the incidences of postoperative complications and ASD. In the present study, patients $>60$ years old with a PI-LL of $>20^{\circ}$ had an increased incidence of ASD (Fig. 4). However, a PILL of $>10^{\circ}$ was associated with a high prevalence of ASD in patients $\leq 60$ years old (Fig. 5). Patients with a PI-LL of $\geq 10^{\circ}$ experience greater shear stresses and compression forces at the intervertebral joints after lumbar fusion compared with those with a PI-LL of $<10^{\circ}$, which may indicate a poor natural history [5]. Figure 6 highlights a patient with a PI-LL of $<10^{\circ}$ and a change in lumbar lordosis of $<10^{\circ}$ were significantly less likely to develop adjacent segment disease.

For every adult, the PI is fixed and is a reliable morphological parameter of the human body. The size of the PI-LL mismatch reveals the relative decrease in LL, resulting in the displacement of the gravity axis of the PI and the inhomogeneity of the sagittal alignment of the spine [23]. When the sagittal plane of the spine is unbalanced, the body will instigate a series of compensatory mechanisms to maintain the balance of the sagittal plane. The first compensatory mechanism of the spine is

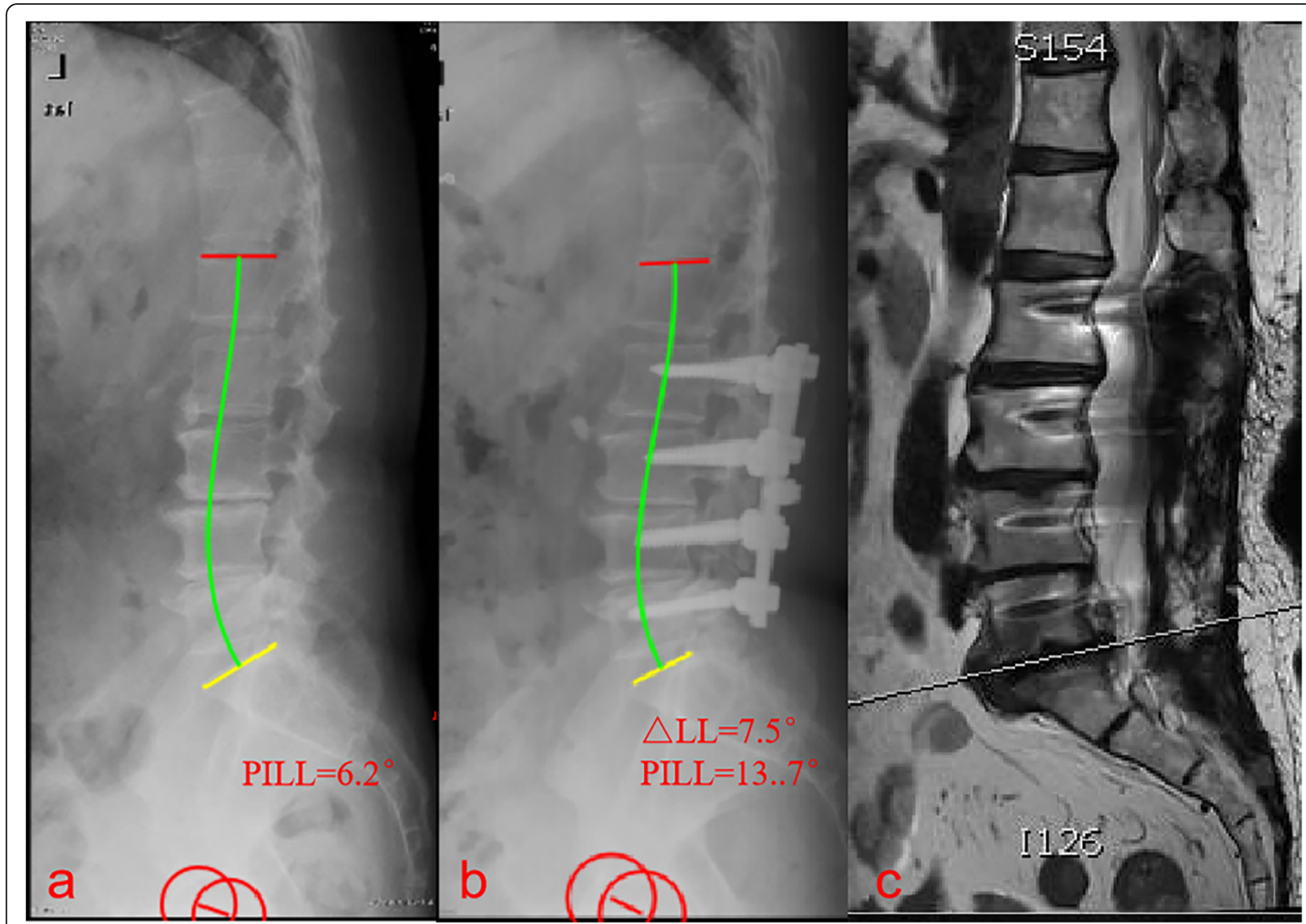

Fig. 5 Images from a 58-year-old man who underwent four-segment spinal fusion. a Preoperative radiograph. b 1-week postoperative radiograph. c MRI revealing the development of symptomatic adjacent segment disease at 2 years and 1 month postoperatively. Preoperatively, the pelvic incidence to lumbar lordosis mismatch (PI-LL) was $6.2^{\circ}$. Postoperatively, the PI-LL was $13.7^{\circ}$ and the change in lumbar lordosis was $7.5^{\circ}$. Patients (age $\leq 60$ ) with a PI-LL of $>10^{\circ}$ were significantly more likely to develop adjacent segment disease 


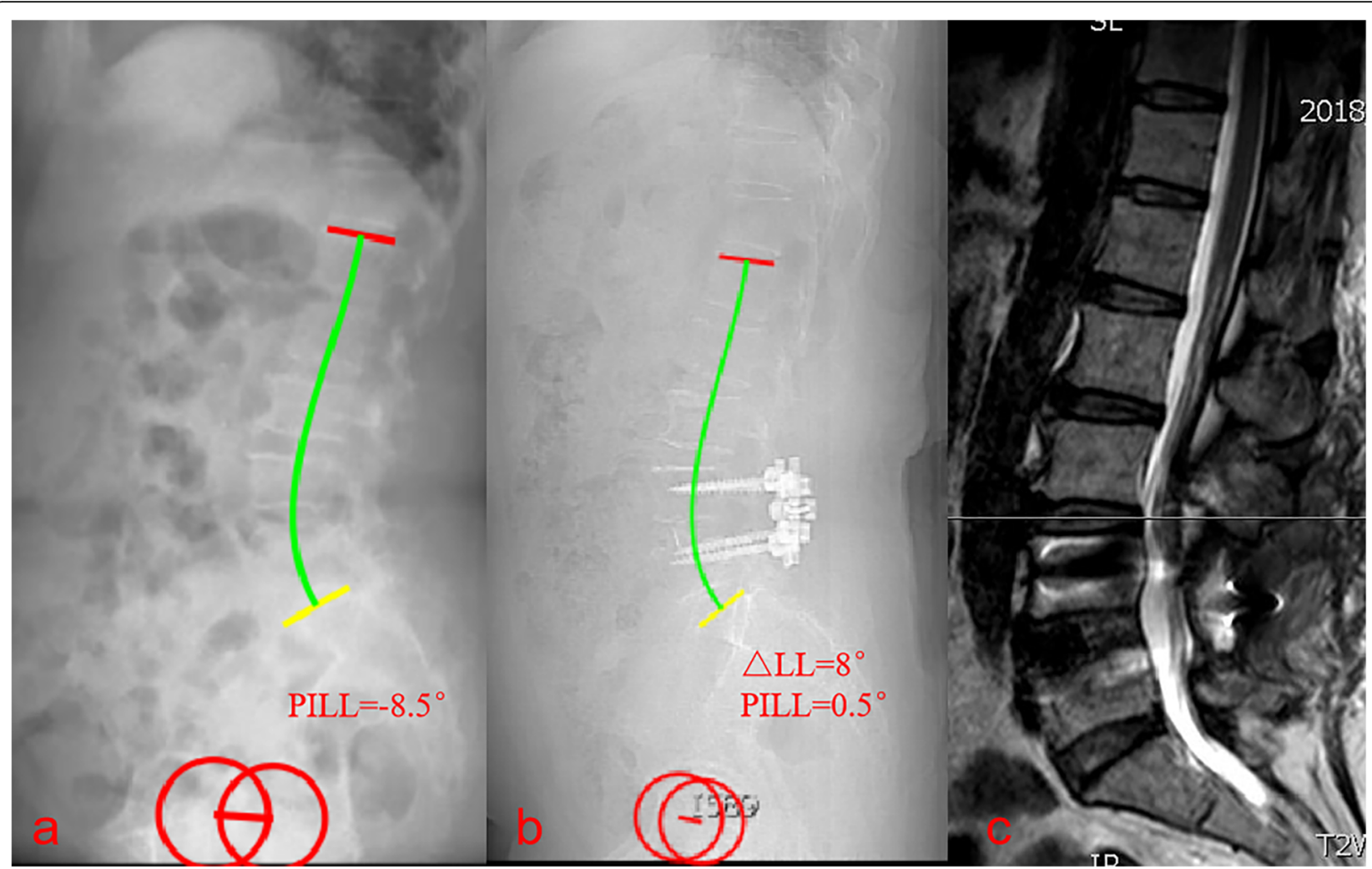

Fig. 6 Images from a 56-year-old woman who underwent one-segment spinal fusion. a Preoperative radiograph. b 1-week postoperative radiograph. c MRI revealing the development of symptomatic adjacent segment disease at 4 years and 6 months postoperatively. Preoperatively, the pelvic incidence to lumbar lordosis mismatch (PI-LL) was $-8.5^{\circ}$. Postoperatively, the PI-LL was $0.5^{\circ}$ and the change in lumbar lordosis was $8^{\circ}$. Patients with a PI-LL of $<10^{\circ}$ and a change in lumbar lordosis of $<10^{\circ}$ were significantly less likely to develop adjacent segment disease

overextension of the thoracic vertebrae, which reduces the thoracic kyphosis [24]. The later compensation tends to manifest as retrodisplacement and posterior translation of the pelvis, along with flexion of the knees and ankles [25]. Clinically, the trunk of older adults is pitched forward due to loss of LL, and so they can withstand degenerative sagittal imbalances. Thus, it may be counterproductive to fully return the spinal curvature to normal in older adults. Our current strategy is to determine the appropriate LL and PI-LL at the time of surgery to prevent ASD via long-term or short-term fusion. To obtain the optimal LL and PI-LL, surgeons should consider using methods such as appropriate hyper wedge cages and the bend screw-rod system that can meet normal physiological curve of the spine.

The present study had some limitations. (1) The data were obtained from cases of spinal surgery performed in a single institution. (2) The relationship between LL and quality of life was not assessed. However, as the assessment was based only on radiological measurements, the data were relatively objective. (3) The optimal LL angle varies in accordance with ethnicity, age, sex, and other variables. Our study cohort only represents a demographically homogenous group of Chinese patients.

\section{Conclusion}

The occurrence of symptomatic ASD after spinal fusion is strongly associated with a smaller LL angle, greater PI-LL mismatch, and excessive $\triangle$ LL. The LL required to prevent symptomatic ASD in older adults differs from that in younger adults, as the ideal correction of LL varies with increasing age. Therefore, these factors should be considered and a corresponding surgical strategy should be selected to reduce the risk of reoperation for ASD.

\section{Abbreviations}

ASDis: Adjacent segment disease; ASD: Adjacent segment degeneration; LL: Lumbar lordosis; PI: Pelvic incidence; SS: Sacral slope; PT: Pelvic tilt; SVA: Sagittal vertical axis; $\triangle \mathrm{LL}$ : Postoperative LL - preoperative LL; LDD: Lumbar degenerative disease; LBP: Low back pain; PLF: Posterolateral fusion; PLIF: Posterior lumbar interbody fusion; BMI: Body mass index; MRI: Magnetic resonance imaging; PSM: Propensity score-matched

\section{Acknowledgements}

Not applicable.

\section{Authors' contributions}

HWX initiated the idea, did the data analysis, SJW and SBZ wrote the assay. YYY and TH supervised and reviewed the manuscript. DSW gathered the data and helped with the data analysis. All authors read and approved the final manuscript. 


\section{Funding}

This work was funded by the National Natural Science Foundation of China (81572181). This work was also funded by a Municipal Human Resources Development Program for Outstanding Young Talents in Medical and Health Sciences in Shanghai (2017YQ070), National Natural Science Foundation of China (81802173) and Program for Young Excellent Talents in Tongji University -Fundamental Research Funds for the Central Universities (22120180598).

\section{Availability of data and materials}

The datasets used and analyzed during the current study are available from the corresponding author on reasonable request.

\section{Ethics approval and consent to participate}

The study protocol was approved by the institutional review board of Shanghai East Hospital and complied with the Good Clinical Practice guidelines and applicable laws and regulations.

\section{Consent for publication}

Not Applicable.

\section{Competing interests}

The authors declare that they have no competing interests.

Received: 17 April 2020 Accepted: 24 June 2020

Published online: 03 July 2020

\section{References}

1. Sato S, Yagi M, Machida M, Yasuda A, Konomi T, Miyake A, Fujiyoshi K, Kaneko S, Takemitsu M, Machida M, Yato Y, Asazuma T. Reoperation rate and risk factors of elective spinal surgery for degenerative spondylolisthesis: minimum 5-year follow-up. Spine J. 2015;15(7):1536-44. https://doi.org/10. 1016/.j.spinee.2015.02.009

2. Lee JC, Kim Y, Soh JW, Shin BJ. Risk factors of adjacent segment disease requiring surgery after lumbar spinal fusion: comparison of posterior lumbar interbody fusion and posterolateral fusion. Spine (Phila Pa 1976). 2014;39(5): E339-45. https://doi.org/10.1097/brs.0000000000000164.

3. Harrop JS, Youssef JA, Maltenfort M, Vorwald P, Jabbour P, Bono CM, Goldfarb N, Vaccaro AR, Hilibrand AS. Lumbar adjacent segment degeneration and disease after arthrodesis and total disc arthroplasty. Spine (Phila Pa 1976). 2008;33(15):1701-7. https://doi.org/10.1097/BRS. Ob013e31817bb956.

4. Davis MA, Onega T, Weeks WB, Lurie JD. Where the United States spends its spine dollars: expenditures on different ambulatory services for the management of back and neck conditions. Spine (Phila Pa 1976). 2012; 37(19):1693-701. https://doi.org/10.1097/BRS.0b013e3182541f45.

5. Senteler M, Weisse B, Snedeker JG, Rothenfluh DA. Pelvic incidence-lumbar lordosis mismatch results in increased segmental joint loads in the unfused and fused lumbar spine. Eur Spine J. 2014;23(7):1384-93. https://doi.org/10. 1007/s00586-013-3132-7.

6. Kim JY, Ryu DS, Paik HK, Ahn SS, Kang MS, Kim KH, Park JY, Chin DK, Kim KS, Cho YE, Kuh SU. Paraspinal muscle, facet joint, and disc problems: risk factors for adjacent segment degeneration after lumbar fusion. Spine J. 2016;16(7):867-75. https://doi.org/10.1016/j.spinee.2016.03.010.

7. Yamasaki $K$, Hoshino M, Omori $K$, Igarashi $H$, Nemoto $Y$, Tsuruta T, Matsumoto K, Iriuchishima T, Ajiro Y, Matsuzaki H. Risk factors of adjacent segment disease after Transforaminal inter-body fusion for degenerative lumbar disease. Spine (Phila Pa 1976). 2017;42(2):E86-e92. https://doi.org/10. 1097/brs.0000000000001728.

8. Tempel Z, Gandhoke GS, Bolinger BD, Khattar NK, Parry PV, Chang YF, Okonkwo DO, Kanter AS. The influence of pelvic incidence and lumbar Lordosis mismatch on development of symptomatic adjacent level disease following single-level Transforaminal lumbar Interbody fusion. Neurosurgery, 2017;80(6):880-6. https://doi.org/10.1093/neuros/nyw073.

9. Lee JH, Kim KT, Lee SH, Kang KC, Oh HS, Kim YJ, Jung H. Overcorrection of lumbar lordosis for adult spinal deformity with sagittal imbalance: comparison of radiographic outcomes between overcorrection and undercorrection. Eur Spine J. 2016;25(8):2668-75. https://doi.org/10.1007/ s00586-016-4441-4.

10. Sadler SG, Spink MJ, Ho A, De Jonge XJ, Chuter VH. Restriction in lateral bending range of motion, lumbar lordosis, and hamstring flexibility predicts the development of low back pain: a systematic review of prospective cohort studies. BMC Musculoskelet Disord. 2017;18(1):179. https://doi.org/10. 1186/s12891-017-1534-0

11. Rothenfluh DA, Mueller DA, Rothenfluh E, Min K. Pelvic incidence-lumbar lordosis mismatch predisposes to adjacent segment disease after lumbar spinal fusion. Eur Spine J. 2015;24(6):1251-8. https://doi.org/10.1007/s00586014-3454-0.

12. Lafage R, Schwab F, Challier V, Henry JK, Gum J, Smith J, Hostin R, Shaffrey C, Kim HJ, Ames C, Scheer J, Klineberg E, Bess S, Burton D, Lafage V. Defining Spino-pelvic alignment thresholds: should operative goals in adult spinal deformity surgery account for age? Spine (Phila Pa 1976). 2016;41(1): 62-8. https://doi.org/10.1097/brs.0000000000001171.

13. Pfirrmann CW, Metzdorf A, Zanetti M, Hodler J, Boos N. Magnetic resonance classification of lumbar intervertebral disc degeneration. Spine (Phila Pa 1976). 2001;26(17):1873-8. https://doi.org/10.1097/00007632-20010901000011.

14. Verbiest $H$. The significance and principles of computerized axial tomography in idiopathic developmental stenosis of the bony lumbar vertebral canal. Spine (Phila Pa 1976). 1979;4(4):369-78. https://doi.org/10. 1097/00007632-197907000-00005.

15. Smith JS, Klineberg E, Schwab F, Shaffrey Cl, Moal B, Ames CP, Hostin R, Fu KM, Burton D, Akbarnia B, Gupta M, Hart R, Bess S, Lafage V. Change in classification grade by the SRS-Schwab adult spinal deformity classification predicts impact on health-related quality of life measures: prospective analysis of operative and nonoperative treatment. Spine (Phila Pa 1976). 2013:38(19):1663-71. https://doi.org/10.1097/BRS.0b013e31829ec563.

16. Schuller S, Charles YP, Steib JP. Sagittal spinopelvic alignment and body mass index in patients with degenerative spondylolisthesis. Eur Spine $J$. 2011;20(5):713-9. https://doi.org/10.1007/s00586-010-1640-2.

17. Been E, Kalichman L. Lumbar lordosis. Spine J. 2014;14(1):87-97. https://doi. org/10.1016/j.spinee.2013.07.464.

18. Lee CS, Chung SS, Park SJ, Kim DM, Shin SK. Simple prediction method of lumbar lordosis for planning of lumbar corrective surgery: radiological analysis in a Korean population. Eur Spine J. 2014;23(1):192-7. https://doi. org/10.1007/s00586-013-2895-1.

19. Xu L, Qin X, Zhang W, Qiao J, Liu Z, Zhu Z, Qiu Y, Qian BP. Estimation of the ideal lumbar Lordosis to be restored from spinal fusion surgery: a predictive formula for Chinese population. Spine (Phila Pa 1976). 2015;40(13):1001-5. https://doi.org/10.1097/brs.0000000000000871.

20. Zhu Z, Xu L, Zhu F, Jiang L, Wang Z, Liu Z, Qian BP, Qiu Y. Sagittal alignment of spine and pelvis in asymptomatic adults: norms in Chinese populations. Spine (Phila Pa 1976). 2014;39(1):E1-6. https://doi.org/10.1097/ brs.0000000000000022.

21. Kim WJ, Ma CH, Kim SH, Min YS, Lee JW, Chang SH, Park KH, Park KY, Song DG, Choy WS. Prevention of adjacent segmental disease after fusion in degenerative spinal disorder: correlation between segmental lumbar Lordosis ratio and pelvic incidence-lumbar Lordosis mismatch for a minimum 5-year follow-up. Asian Spine J. 2019;13(4):654-62. https://doi.org/ 10.31616/asj.2018.0279

22. Schwab FJ, Blondel B, Bess S, Hostin R, Shaffrey Cl, Smith JS, Boachie-Adjei O, Burton DC, Akbarnia BA, Mundis GM, Ames CP, Kebaish K, Hart RA, Farcy $J P$, Lafage $V$. Radiographical spinopelvic parameters and disability in the setting of adult spinal deformity: a prospective multicenter analysis. Spine (Phila Pa 1976). 2013;38(13):E803-12. https://doi.org/10.1097/BRS. Ob013e318292b7b9.

23. Barrey C, Roussouly P, Le Huec JC, D'Acunzi G, Perrin G. Compensatory mechanisms contributing to keep the sagittal balance of the spine. Eur Spine J. 2013;22(Suppl 6):S834-41. https://doi.org/10.1007/s00586-013-3030-z.

24. Jang JS, Lee $\mathrm{SH}$, Min JH, Maeng $\mathrm{DH}$. Changes in sagittal alignment after restoration of lower lumbar lordosis in patients with degenerative flat back syndrome. J Neurosurg Spine. 2007;7(4):387-92. https://doi.org/10.3171/spi07/10/387.

25. Barrey C, Roussouly P, Perrin G, Le Huec JC. Sagittal balance disorders in severe degenerative spine. Can we identify the compensatory mechanisms? Eur spine J 20 Suppl 5:626-633. 2011. https://doi.org/10.1007/s00586-0111930-3.

\section{Publisher's Note}

Springer Nature remains neutral with regard to jurisdictional claims in published maps and institutional affiliations. 